\title{
Isolation, cultivation and molecular characterization of a new Trypanosoma equiperdum strain in Mongolia
}

Keisuke Suganuma ${ }^{1 \dagger}$, Sandagdorj Narantsatsral ${ }^{2 \dagger}$, Banzragch Battur ${ }^{2}$, Shino Yamasaki ${ }^{1}$, Davaajav Otgonsuren ${ }^{2}$, Simon Peter Musinguzi ${ }^{1}$, Batdorj Davaasuren ${ }^{1,2}$, Badgar Battsetseg $^{2}$ and Noboru Inoue ${ }^{1 *}$

\begin{abstract}
Background: Trypanosoma equiperdum causes dourine via sexual transmission in Equidae. T. equiperdum is classified under the subgenus Trypanozoon along with the T. brucei sspp. and T. evansi; however, the species classification of Trypanozoon remains a controversial topic due to the limited number of T. equiperdum reference strains. In addition, it is possible that some were misclassified T. evansi strains. Thus, there is a strong need for a new T. equiperdum strain directly isolated from the genital mucosa of a horse with a clinically- and parasitologically-confirmed dourine infection.

Methods: Trypanosomes isolated from the urethral tract of a stallion with suspected dourine, were directly cultivated using soft agarose media at $37^{\circ} \mathrm{C}$ in $5 \% \mathrm{CO}_{2}$. For molecular characterization, $18 \mathrm{~S}$ ribosomal RNA (rRNA) gene, the internal transcribed spacer (ITS) and 8 maxicircle DNA regions were amplified by a PCR and their sequences were determined. To analyze the ratio of the kinetoplastic/akinetoplastic population, the kinetoplasts and the nuclei of trypanosomes were subjected to Hoechst staining and observed by fluorescence microscopy.
\end{abstract}

Results: In addition to the clinical symptoms and the molecular diagnosis, this stallion was definitively diagnosed with dourine by the detection of trypanosomes in the urethral mucosa. These results strongly suggested that the isolated trypanosome was true T. equiperdum. T. equiperdum isolated from the urethral tract was adapted in vitro using soft agarose media. Based on the results of a phylogenetic analysis of $18 \mathrm{~S} \mathrm{rRNA}$ and ITS, this T. equiperdum isolate was classified into the Trypanozoon clade. In a PCR of the maxicircle DNA region, only NADH-dehydrogenase subunits 4 and 5 was amplified. Clear kinetoplasts were observed in most of the T. equiperdum isolates. In contrast, most cultureadapted T. equiperdum were of the akinetoplastic form.

Conclusion: We concluded that our isolated trypanosome was the first confirmed case of T. equiperdum in Mongolia and named it "T. equiperdum IVM-t1". T. equiperdum IVM-t1 was well adapted and propagated in soft agarose media, which indicates that this culture method is useful for isolation of T. equiperdum from horses with dourine.

Keywords: Dourine, In vitro culture, Maxicircle DNA, Mongolia, Soft agarose media, Trypanosoma equiperdum

Abbreviations: $18 \mathrm{~S}$ rRNA, $18 \mathrm{~S}$ ribosomal RNA; ALP, Alkaline phosphatase; ALT, Alanine transaminase; AST, Aspartate aminotransferase; BUN, Blood urea nitrogen; CFT, Complement fixation test; CSF, Cerebrospinal fluid; ELISA, Enzymelinked immunosorbent assay; HCT, Hematocrit; HGB, Hemoglobin; HMI-9, Hirumi's modified Isocove's medium-9; ICT, Immunochromatographic test; ITS, Internal transcribed spacer; kDNA, Kinetoplast DNA; MCH, Mean corpuscular hematocrit; MCHC, Mean corpuscular hemoglobin concentration; MCV, Mean corpuscular volume; ND4-ND5, NADHdehydrogenase subunits 4 and 5; PLT, Platelet; RBC, Red blood cell; WBC, White blood cell

\footnotetext{
*Correspondence: ircpmi@obihiro.ac.jp

'Equal contributors

${ }^{1}$ National Research Center for Protozoan Diseases, OIE Reference Laboratory

for Surra, Obihiro University of Agriculture and Veterinary Medicine, Inada,

Obihiro, Hokkaido 080-8555, Japan

Full list of author information is available at the end of the article
} 


\section{Background}

Dourine is caused by Trypanosoma equiperdum of the subgenus Trypanozoon. Unlike other trypanosomes, dourine is not transmitted by insect vectors; rather, it is transmitted by the infected horse via coitus. Thus, dourine has previously been distributed worldwide [1].

Subgenus Trypanozoon includes three subspecies of $T$. brucei. (T. brucei brucei, T. b. gambiense and T. b. rhodesiense), T. evansi and T. equiperdum. T. brucei, T. evansi and $T$. equiperdum have been classified based on their kinetoplast DNA (kDNA) components: T. brucei contains complete maxicircle kDNA, $T$. evansi completely lacks maxicircle $\mathrm{kDNA}$, while the integrity of the maxicircle kDNA of $T$. equiperdum varies in each strain. Nevertheless, its classification within the subgenus Trypanozoon remains a controversial topic because it has been hypothesized that a very close evolutionary relationship exists among the trypanosome species of Trypanozoon [2, 3]. Moreover, many of T. equiperdum strains were isolated over 50 years ago, and it was hypothesized that some of the isolates were misclassified T. evansi strains [3]. Some of the new T. equiperdum strains were recently isolated in Italy and Ethiopia from horses with suspected dourine infections $[4,5]$. However, these $T$. equiperdum strains were not directly isolated from the genital mucosa (the primary site of infectious lesions of $T$. equiperdum). Instead, they were isolated from udder secretion samples or jugular venous blood. Thus, new $T$. equiperdum strains that are directly isolated from the infectious lesions of horses with clinically- and parasitologically-confirmed dourine have long been needed for further studies on T. equiperdum and dourine.

Previous reports have shown the prevalence of equine trypanosomosis in Mongolia and Kazakhstan to be 6-8 \% and $16.8 \%$, respectively $[6,7]$. However, these reports did not identify the causative species because it is very difficult to distinguish T. equiperdum from $T$. evansi using serological diagnostic techniques. On the other hand, the re-emergence of dourine was reported in Italy in May 2011 when the characteristic symptoms of dourine (e.g. paralysis of the lip, edema of the vulva and cutaneous wheals) were observed in a number of horses [8]. A serological test revealed that approximately $0.5 \%$ of the equine population was diagnosed as dourine-positive by CFT, moreover, dourine positivity (based on the case definition) has been confirmed in $0.03 \%$ of all horses [9]. Moreover, trypanosomes were observed in the skin lesions and were isolated from infected horses by intrascrotal inoculation [5].

Our ongoing epidemiological research suggests high prevalence of trypanosomoses in horses in Mongolia. In the present study, dourine was diagnosed parasitologically via the detection of T. equiperdum in the urethral tract of a stallion with the characteristic clinical symptoms. Moreover, we established a new true $T$. equiperdum strain that was isolated from the urethral tract of a dourine-infected stallion. Furthermore, we used a PCR to molecularly characterize this new strain of T. equiperdum.

\section{Methods}

The identification of the stallion with suspected dourine

The brown-colored 7-year-old stallion was bred in an equestrian farm in Töv aimag in Mongolia. It was suspected of being infected with dourine based on the presence of slight paraphimosis and edema in the genital organ (Fig. 1a and b). The blood parameters (white blood cell [WBC], red blood cell [RBC], hemoglobin [HGB], hematocrit $[\mathrm{HCT}]$, mean corpuscular volume [MCV], mean corpuscular hematocrit $[\mathrm{MCH}]$, mean corpuscular hemoglobin concentration $[\mathrm{MCHC}]$, and platelet [PLT] count) were measured using a Celltac $\alpha$ (Nihon Khoden, Tokyo, Japan); while the measurement of the blood chemistry parameters (alkaline phosphatase [ALP], alanine transaminase [ALT], aspartate aminotransferase $[\mathrm{AST}]$, albumin, total protein, total cholesterol, bilirubin, blood urea nitrogen [BUN], creatinine, and amylase) was outsourced (Table 1). Molecular diagnoses were then performed using DNA extracted from the blood and serum of the stallion by a KIN-PCR, a complement fixation test (CFT), a recombinant T. evansi GM6-4r antigen-based immunochromatographic test (ICT) and an enzyme-linked immunosorbent assay (ELISA) [10-13]. The collected cerebrospinal fluid (CSF) was centrifuged to concentrate the trypanosomes. Trypanosomes in the sediment of the CSF and in the blood were observed by the wet blood film method. Parasitemia in the blood was estimated using Herbert \& Lumsden's method [14].

\section{Isolation and cultivation of $T$. equiperdum in vitro}

To isolate T. equiperdum from the urethral tract of the stallion, Hirumi's modified Iscove's medium-9 supplemented with $20 \%$ heat-inactivated adult horse serum (HMI-9) [15] was injected into the urethral tract of the stallion with a suspected dourine infection to detach $T$. equiperdum from the urethral tract mucosa (Fig. 1c). Subsequently, T. equiperdum was sampled from the urethral tract mucosa using a cotton swab (Fig. 1d). The $T$. equiperdum specimens from the urethral tract mucosa were smeared on slide glasses, fixed with $100 \%$ methanol and stained with Giemsa for microscopic observation. The major axis of isolated T. equiperdum was measured using a Nikon Eclipse Ci microscope and the Nice D software program (Nikon Corporation, Tokyo, Japan).

The $T$. equiperdum isolates from the urethral tract were centrifuged with HMI-9 media at 3000× $g$ for $10 \mathrm{~min}$ at room temperature. The pellets containing $T$. 

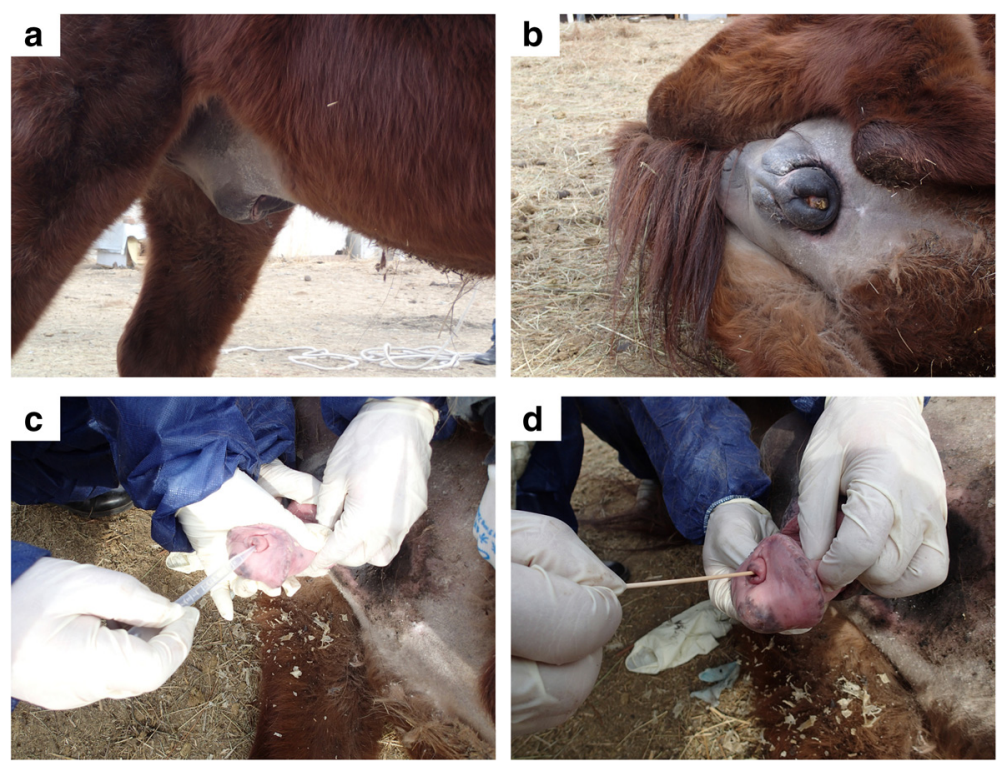

Fig. 1 The swelling of the genital organ of the dourine-infected stallion and sampling of trypanosomes from the urethral tract. $\mathbf{a}$ and $\mathbf{b}$ The swelling of the genital organ of the dourine-infected stallion. $\mathbf{c ~ H M I - 9}$ was injected into the urethral tract using a transfer pipette to detach adherent $T$. equiperdum from the urethral tract mucosa. $\mathbf{d}$ Sampling of T. equiperdum from the urethral tract mucosa using a cotton swab

equiperdum and urethral mucosa cells were washed twice with HMI-9. Finally, T. equiperdum suspended in HMI-9 was spread on soft agarose media (HMI-9 with $0.8 \%$ low gelling agarose [Type VII, Sigma-Aldrich Japan, Tokyo, Japan]) at $37{ }^{\circ} \mathrm{C}$ in $5 \% \mathrm{CO}_{2}$. Cultureadapted T. equiperdum specimens were cryopreserved in

Table 1 The clinical symptoms, blood parameters and blood chemistry of the dourine-infected stallion

\begin{tabular}{|c|c|}
\hline \multirow[t]{5}{*}{ Clinical symptoms } & Slight edema in the genital organ \\
\hline & Slight paraphimosis \\
\hline & A large amount of smegma around the penis \\
\hline & Small skin lesion \\
\hline & Slight anemia \\
\hline \multirow[t]{5}{*}{ Blood parameters } & WBC: $12.9 \times 10^{3}$ cells $/ \mu \mathrm{l}$ (slightly high) \\
\hline & RBC: $6.32 \times 10^{6}$ cells $/ \mu$ l (slightly low) \\
\hline & HGB: 10.6 g/dl (slightly low) \\
\hline & HCT: 30.9 \% (slightly low) \\
\hline & Other parameters: normal (MCV, MCH, MCHC, PLT) \\
\hline $\begin{array}{l}\text { Blood chemistry } \\
\text { parameters }\end{array}$ & $\begin{array}{l}\text { Normal (ALP, ALT, AST, albumin, total protein, total } \\
\text { cholesterol, bilirubin, BUN, creatinine, amylase) }\end{array}$ \\
\hline \multirow[t]{3}{*}{ Parasitemia } & $\begin{array}{l}\text { Swab of the urethral tract mucosa: a lot of } \\
\text { trypanosomes }\end{array}$ \\
\hline & $\begin{array}{l}\text { Blood: }<2.5 \times 10^{5} \text { cells } / \mathrm{ml}^{\mathrm{a}}(1 \text { trypanosome per } \\
500 \text { fields; magnification } 400 \times \text { ) }\end{array}$ \\
\hline & $\begin{array}{l}\text { Cerebrospinal fluid: relatively a lot of } \\
\text { trypanosomes in sediment }\end{array}$ \\
\hline
\end{tabular}

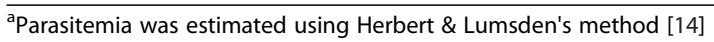

horse serum supplemented with $10 \%$ dimethyl sulfoxide at $-80{ }^{\circ} \mathrm{C}$.

\section{DNA extraction}

Total DNA of T. equiperdum was extracted and purified using TE-saturated phenol (Sigma-Aldrich, Japan) and phenol-chloroform-isoamyl alcohol solution (SigmaAldrich, Japan) [16]. Purified DNA was kept at $-30{ }^{\circ} \mathrm{C}$ until use.

\section{PCR amplification and phylogenetic analysis of $18 \mathrm{~S}$ rRNA gene and ITS}

The 18S ribosomal RNA (18S rRNA) gene and the internal transcribed spacer (ITS) region of the Mongolian isolate and the reference strains of T. equiperdum (the total DNA of the STIB818, STIB841, STIB842 and BoTat1.1 strains were all kindly provided by Dr. ZhaoRong Lun of Sun Yat-Sen University in the People's Republic of China) were amplified and cloned into the pCR 2.1 cloning vector (Thermo Fisher Scientific K.K., Tokyo, Japan), and the sequences were analyzed using an ABI3100 genomic analyzer (Thermo Fisher Scientific K.K.) [17]. In addition to these T. equiperdum sequence data, the reference sequences from the NCBI database (T. brucei [Accession No. AC012647.18], T. b. rhodesiense [AJ009142], T. b. gambiense [FN554966.1 and AJ009141] and T. evansi [AB551922.1, AY912277, AY912279 and D89527.1]) were included in the phylogenetic analyses. The phylogenetic analyses of the $18 \mathrm{~S}$ rDNA 
and ITS regions were performed using the neighborjoining method using the MEGA 7 software program.

\section{Maxicircle kDNA characterization}

The target loci on the maxicircle genes were amplified from the total DNA of the Mongolian T. equiperdum isolate. In addition, the total DNA from $T . b$. brucei GUTat3.1, T. evansi IL3960 and T. equiperdum STIB818, STIB841, STIB842 and BoTat1.1 were used for maxicircle gene amplification in order to compare the maxicircle kinetoplast DNA (kDNA) sequences among the trypanosome species. The primer sequences for each of the target loci on the maxicircle gene have been described previously (Additional file 1: Table S1) [18]. The amplicons were cloned into pCR 2.1 cloning vector (Thermo Fisher Scientific K.K.), and the sequences were analyzed using an ABI3100 genomic analyzer (Thermo Fisher Scientific K.K.).

\section{The measurement of kinetoplastic and akinetoplastic $T$.} equiperdum population

Culture-adapted T. equiperdum and T. equiperdum that were directly obtained from the urethral tract and CSF of an infected stallion were spread over glass slides printed with highly water-repellent marking (Matsunami Glass Ind., Ltd., Tokyo, Japan), air-dried, and fixed with $100 \%$ methanol for $10 \mathrm{~min}$ at room temperature. The specimens were blocked with $5 \%$ skim milk in TBS supplemented with $0.05 \%$ tween for $1 \mathrm{~h}$ at room temperature. The specimens were then incubated with a primary antibody (anti-recombinant $T$. congolense $\alpha$ tubulin serum) [19]. Next, the slides were incubated with a secondary antibody (Alexa Fluor 488 goat antirabbit IgG $[\mathrm{H}+\mathrm{L}]$, Thermo Fisher Scientific K.K.) with Hoechst 33342 (Dojindo, Co. Ltd., Kumamoto, Japan). The specimens were observed by confocal laser scanning microscopy (Leica TCS SP5, Leica Microsystems, Wetzlar, Germany).

\section{Results}

\section{T. equiperdum isolated from the urethral tract of the} dourine-infected stallion

Dourine was suspected based on the swelling of the genital organ, slight paraphimosis, a large amount of smegma and a small skin lesion on the stallion (Fig. 1a and $\mathrm{b}$ ). In addition, slight anemia was suggested based on a hematological examination (Table 1). Moreover, the CFT, ICT and ELISA results strongly suggested a trypanosome infection (data not shown). However, these molecular diagnostic methods were not capable of differentiating between $T$. equiperdum and T. evansi. Thus, we could not eliminate the possibility of a $T$. evansi infection (Surra) based on these results. In addition to suspecting dourine based on the clinical symptoms and the molecular diagnostic results, actively moving trypanosomes were detected from the mucosa of the urethral tract by microscopy. Moreover, the parasitemia in the blood was very low, while that in the sediment of the CSF was relatively high (Table 1). We therefore concluded that this stallion was infected with $T$. equiperdum. The microscopic observation of Giemsa-stained trypanosomes was used for the morphological characterization of the $T$. equiperdum isolate of the naturally infected stallion. Kinetoplasts were clearly stained and observed in all of the trypanosomes. Single-form and dividing-form (2K1N and $2 \mathrm{~K} 2 \mathrm{~N})$ trypanosomes with a free flagellum were observed (Fig. 2). The major axis of the trypanosomes was $26.4 \pm$ $3.1 \mu \mathrm{m}$ (mean \pm standard deviation, $n=27$ ).

\section{Culture adaptation of the $T$. equiperdum isolate}

$T$. equiperdum isolated from urethral tract of the dourine-infected stallion was directly transferred into an in vitro culture. They were adapted in a soft agarose media culture system. Unlike the culturing of other bloodstream-form trypanosomes, the primary culture of isolated T. equiperdum could not be successfully propagated in HMI-9 liquid media. The parasites were found to be attached and actively moving on the surface of soft agarose media (Additional file 2: Movie 1). Some of them invaded the soft agarose and propagate under the surface of soft agarose during cultivation. Unlike T. bru$c e i$, they could not form colonies on the surface of soft agar [20]. This new culture-adapted T. equiperdum strain was named, "IVM-t1 (T. equiperdum isolated in the Institute of Veterinary Medicine from Töv aimag dourine horse no. 1), 2015."

\section{Phylogenetic analyses}

The phylogenetic relationships were inferred from a comparison of the 18S rRNA and ITS sequences of $T$. equiperdum and other Trypanozoon. Like the other $T$. equiperdum strains, the newly isolated T. equiperdum IVM-t1 strain belonged to the Trypanozoon clade (Additional file 3: Figure S1).

\section{T. equiperdum IVM-t1 strain lacks maxicircle integrity}

Eight PCRs targeting the maxicircle genes were performed to compare the maxicircle integrity among the Trypanozoon parasites. The maxicircle PCR of T. evansi IL3960, T. brucei GUTat3.1 and T. equiperdum STIB818, STIB841, STIB842 and BoTat1.1 strains (as the reference strains) showed the same results as previous reports (Table 2) [18]. On the other hand, only NADHdehydrogenase subunits 4 and 5 (ND4-ND5) was amplified in T. equiperdum IVM-t1 strain (Table 2, Fig. 3 and Additional file 3: Figure S2). The PCR signal of ND4-ND5 in the T. equiperdum IVM-t1 strain was somewhat weaker than the ND4-ND5 signals of the other trypanosomes. 

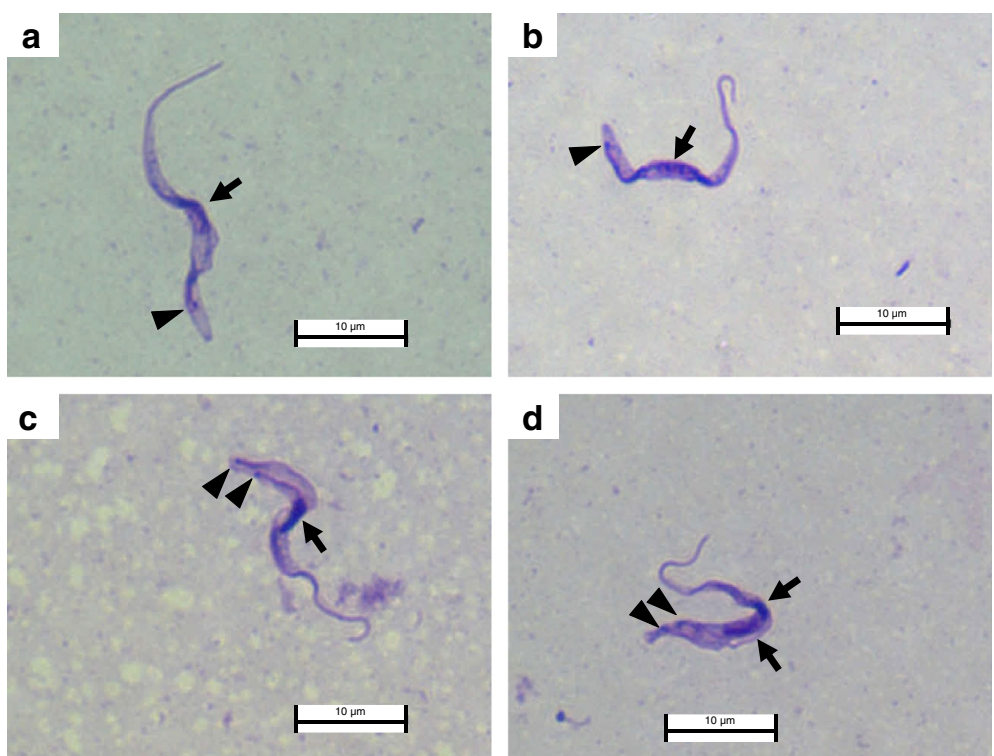

Fig. 2 Giemsa-stained T. equiperdum isolated from the urethral tract of the dourine-infected stallion. $\mathbf{a}$ and $\mathbf{b}(1 \mathrm{~K} 1 \mathrm{~N})$ show the single form of $T$. equiperdum. c $(2 \mathrm{~K} 1 \mathrm{~N})$ and $\mathbf{d}(2 \mathrm{~K} 2 \mathrm{~N})$ show the dividing form of T. equiperdum. Arrow: nucleus; arrowhead: kinetoplast

Sequence analyses showed that the other bright PCR bands (e.g. around the $1.5 \mathrm{kbp}$ band in lane 3 of Additional file 3: Figure S2-A) were not the maxicircle target genes.

\section{The majority of the culture-adapted $T$. equiperdum} IVM-t1 strain population was akinetoplastic after long-term in vitro cultivation

Kinetoplasts were clearly observed in almost all of the $T$. equiperdum specimens from the urethral tract by Giemsa and DNA staining (1 out of 160 [0.63 \%] trypanosomes were akinetoplastic) (Figs. 2 and 4a). In addition, akinetoplastic $T$. equiperdum accounted for a minor part of the trypanosome population in the CSF (6 out of 326
[1.84 \%] of the trypanosomes were akinetoplastic). On the other hand, kinetoplasts were not observed in most of the culture-adapted from T. equiperdum IVM-t1 strain (480 out of 500 [96.0\%] trypanosomes were akinetoplastic) (Fig. 4b).

\section{Discussion}

T. equiperdum is a cosmopolitan trypanosome that causes dourine via sexual transmission in the Equidae. The phylogenetic relationships of the subgenus Trypanozoon (T. brucei sspp., T. evansi and T. equiperdum) have been unclear, and serological methods for differentially diagnosing the various Trypanozoon trypanosomes have not been established due to the lack of information about

Table 2 Summary of the maxicircle PCR results

\begin{tabular}{|c|c|c|c|c|c|c|c|}
\hline \multirow[t]{2}{*}{ Target locus $^{a}$} & \multirow{2}{*}{$\begin{array}{l}\text { T. b. brucei } \\
\text { GUTat3.1 }\end{array}$} & \multirow{2}{*}{$\begin{array}{l}\text { T. evansi } \\
\text { IL3960 }\end{array}$} & \multicolumn{5}{|c|}{ T. equiperdum } \\
\hline & & & IVM-t1 & STIB818 & STIB841 & STIB842 & BoTat1.1 \\
\hline NAD7 & $P$ & $N$ & $N$ & $N$ & $P$ & $P$ & $P$ \\
\hline $\operatorname{Cox} 2$ & $P$ & N & $N$ & $\mathrm{~N}$ & $P$ & $P$ & $P$ \\
\hline A6 & $P$ & N & $N$ & $N$ & $P$ & $P$ & $P$ \\
\hline 125 rRNA & $P$ & N & $N$ & $P$ & $P$ & $P$ & $P$ \\
\hline ND7-CyB & $P$ & N & $N$ & $N$ & $P$ & $P$ & $P$ \\
\hline MURF1-ND1 & $P$ & N & $N$ & $N$ & $P$ & $P$ & $P$ \\
\hline MURF2-Cox1 & $P$ & N & $N$ & $N$ & $P$ & $P$ & $P$ \\
\hline ND4-ND5 & $P$ & $N$ & $P$ & $P$ & $P$ & $P$ & $P$ \\
\hline
\end{tabular}

All of the PCR product sequences were confirmed by a sequence analysis and the NCBI BlastN software program Abbreviations: P Positive, $N$ Negative

${ }^{a}$ NAD7, NADH-dehydrogenase subunit 7; Cox2, Cytochrome oxidase subunit 2; A6, ATPase subunit 6; 12S rRNA, 12S ribosomal RNA; ND7-CyB, NADH-dehydrogenase subunit 7-cytochrome b; MURF-ND1, Maxicircle unknown reading frame-NADH dehydrogenase subunit 1; MURF2-Cox1, Maxicircle unknown reading frame 2-cytochrome oxidase subunit 1 and ND4-ND5, NADH-dehydrogenase subunits 4-5 


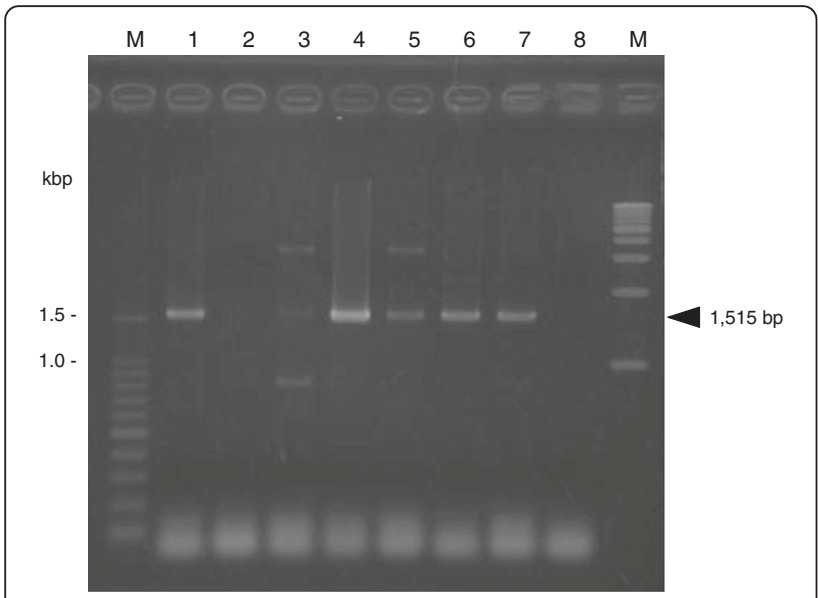

Fig. 3 The PCR to detect NADH-dehydrogenase subunits 4 and 5 (ND4-ND5). A gel electrophoresis image of the PCR products of NADH-dehydrogenase subunits 4 and 5 (ND4-ND5). The arrowhead at $1515 \mathrm{bp}$ indicates the amplicon of ND4-ND5 in lanes 1 and 3 to 7. M: $100 \mathrm{bp}$ and $1 \mathrm{kbp}$ DNA ladders, Lanes 1 to 8 are T. $b$. brucei GUTat3.1, T. evansi IL3960, T. equiperdum IVM-t1, STIB818, STIB841, STIB842, BoTat1.1 strains and a negative control (distilled water), respectively

the T. equiperdum genome. Many of the T. equiperdum strains were isolated more than 50 years ago [3]. Recently new T. equiperdum strains were isolated from horses with suspected dourine in Italy and Ethiopia [4, 5]. However, these T. equiperdum strains were not directly isolated from the genital mucosa (infectious lesion of $T$. equiper$d u m)$. In the present study, we isolated T. equiperdum from the urethral tract of a dourine-infected stallion and established a new culture-adapted $T$. equiperdum strain. Moreover, we conducted the molecular characterization of this T. equiperdum strain based on the $18 \mathrm{~S}$ rRNA, ITS and maxicircle gene sequences.

In addition to the clinical symptoms that led us to suspect dourine and the results of the molecular diagnosis, live trypanosomes were observed on a wet smear from the urethral tract mucosa of one stallion in Mongolia (Table 1). Moreover, trypanosomes were detected in the blood $\left(<2.5 \times 10^{5}\right.$ cells $/ \mathrm{ml}$ ) and CSF (relatively high parasitemia was observed in the sediment) (Table 1). Although T. equiperdum mainly parasitizes in the tissue, it is rarely observed in the bloodstream of horses with chronic infection [1]. We therefore concluded that this stallion was infected with $T$. equiperdum. Since the dividing-form and actively moving trypanosomes were observed, it was concluded that $T$. equiperdum parasites were propagating in the urethral tract mucosa and that they caused dourine in this stallion (Fig. 2). Our ongoing surveillance project in Mongolia also revealed Surra epidemics in other domestic animals (data not shown). Previous reports showed that Tabanus spp. were trapped in Hustai National Park, Mongolia [21]. These results indicated that the Tabanus spp. that can transmit T. evansi can be found in Mongolia. Although the parasitemia was

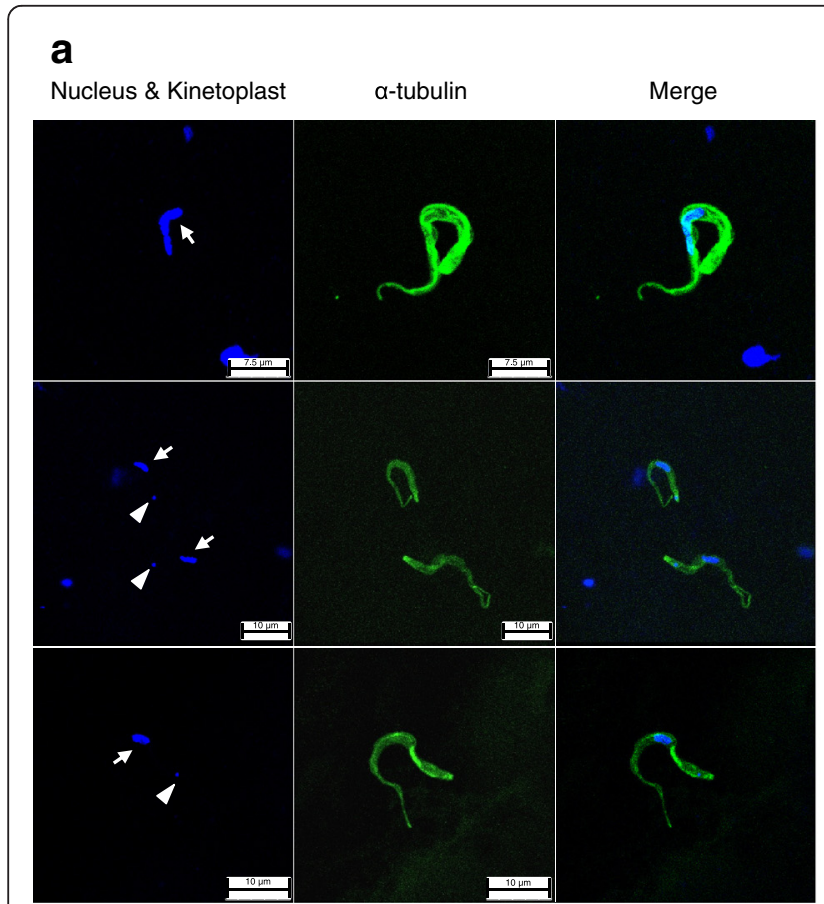

b

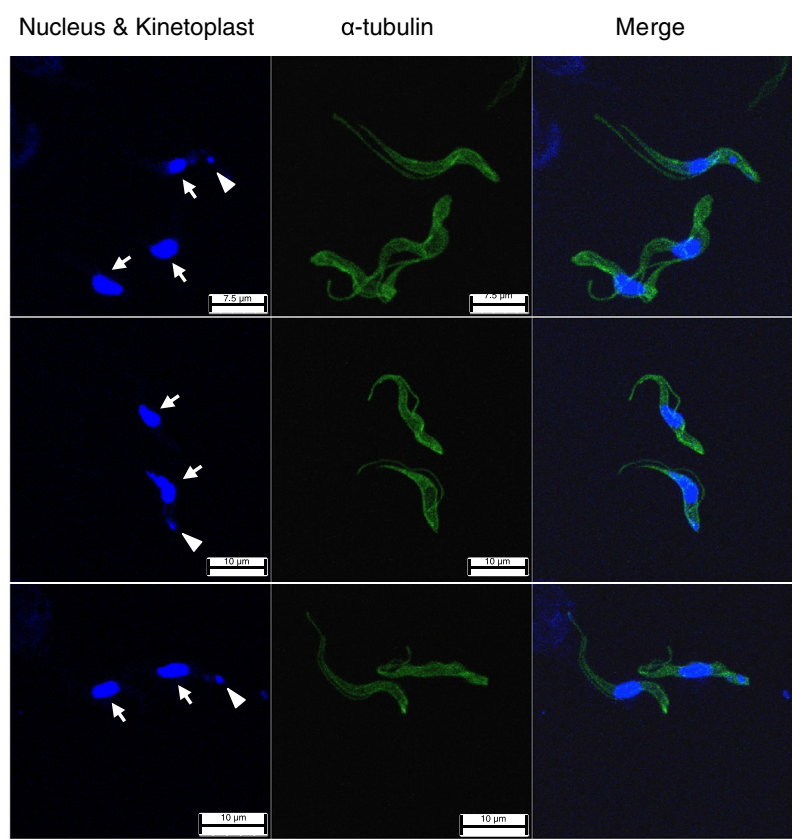

Fig. 4 Akinetoplastic and kinetoplastic T. equiperdum in wild-type and in vitro culture. a T. equiperdum isolated from the urethral tract. Upper panel, akinetoplastic form; middle and lower panels, kinetoplastic form. b Kinetoplastic and akinetoplastic T. equiperdum in vitro culture. Arrow: nucleus; arrowhead: kinetoplast 
very low, T. equiperdum parasitized the bloodstream in this infected stallion. We therefore could not completely exclude the possibility of the mechanical transmission of T. equiperdum due to blood sacking by the Tabanus spp.

Isolated T. equiperdum parasites were adapted and proliferated well using HMI-9 soft agarose media as a primary trypanosome culture (Additional file 2: Movie 1). While isolated, T. equiperdum could not be propagated in HMI9 liquid media in primary trypanosome cultures. Furthermore, unlike $T$. brucei, to proliferate on the surface of the soft agarose media, T. equiperdum invaded the surface of soft agarose media but could not form colonies [20]. After the infection of the genital mucosa via coitus, T. equiper$d u m$ invade the tissue and parasitize in the blood, lymph, CSF and sub-cutaneous lesions [5]. These results suggest that the soft agarose media mimics the natural environment of the host genital mucosa. Thus, the isolated $T$. equiperdum were well adapted and proliferated using soft agarose media but did not adapt in liquid media. This culture system will be useful for the future isolation of $T$. equiperdum from dourine-infected horses in the field.

A phylogenetic analysis using $18 \mathrm{~S}$ rRNA and the ITS region revealed that, along with the other T. equiperdum strains, the T. equiperdum IVM-t1 strain was a member of the Trypanozoon clade (Additional file 3: Figure S1). T. equiperdum and T. evansi were hypothesized to have independently evolved from ancestral T. brucei at least four times [22, 23]. Thus, T. equiperdum is a polyphyletic group and, based on the results of a previous gnomic analysis, is considered to be a subspecies of $T$. brucei. However, Desquesnes et al. [24] suggested that $T$. equiperdum and T. evansi should keep their current species status based on the significant biological and parasitical differences between these species. A RoTat 1.2 VSG PCR, which was performed to analyze the sequence of the amplicon, was negative (data not shown). Moreover, only NADH-dehydrogenase subunit 4 and 5 (ND4-ND5) was amplified in the maxicircle of this strain of T. equiperdum (Table 2 and Fig. 3). The majority of the culture-adapted $T$. equiperdum IVM-t1 strain population was composed of akinetoplastic-form parasites; thus, the weak ND4-ND5 signal was caused by the small amount of maxicircle template DNA because of the small population in kinetoplastic culture-adapted T. equiperdum IVM-t1. The results of this molecular analysis also supported that this isolated trypanosome was T. equiperdum.

Many of the akinetoplastic Trypanozoon trypanosome strains have been established from a parental kinetoplastic strain by the supplementation of DNA binding drugs or RNA interference during in vitro culture [25]. The predominance of the akinetoplastic T. evansi and T. equiper$d u m$ population was also induced from a kinetoplastic parental trypanosome by long-term aseptic cultivation [26]. In the present study, the T. equiperdum IVM-t1 strain was cultivated without any drug supplementation based on the intention to remove kinetoplasts from the kinetoplastic parental T. equiperdum over a one-year cultivation period. However, the majority of the population $(96.0 \%)$ in culture-adapted $T$. equiperdum IVM-t1 strain was akinetoplastic-form, despite akinetoplastic $T$. equiperdum being a minority population in the parental $T$. equiperdum population (0.63\%) (Fig. 4). We cannot conclude that the predominance of akinetoplastic forms in the culture-adapted $T$. equiperdum IVM-t1 strain were simply selected from parental akinetoplastic $T$. equiperdum, which was the minority population in the urethral tract, or induced rapid kinetoplast loss from the parental kinetoplastic $T$. equiperdum during long-term in vitro cultivation without any drug supplementation. The rapid loss of kinetoplasts in culture-adapted T. equiperdum IVM-t1 strain might be due to the acquisition of a rapid proliferative potential in the culture, similarly to the proliferation of unregulated cancer cells in the host [27]. T. equiperdum is usually distinguished from T. evansi by an analysis of the kDNA (by a PCR); however, it was not possible to detect dyskinetoplastic $T$. equiperdum strains (such as the culture-adapted T. equiperdum IVM-t1 strain) by an analysis of the kDNA. Other species-specific markers are therefore expected to be useful for the definitive diagnosis of Trypanozoon infections. We performed a further comparative whole genomic analysis and transcriptome analysis using a next generation sequencing technique to compare the T. equiperdum IVM-t1 strain with other Trypanozoon species. Based on these results, we intend to develop T. equiperdum-specific PCR methods and serodiagnostic methods that can be used to definitively diagnose Trypanozoon infections and reveal the evolution, origin and pathogenic effects of Trypanozoon.

\section{Conclusions}

In conclusion, we successfully isolated T. equiperdum from the urethral tract mucosa of a dourine-infected stallion with characteristic clinical symptoms using soft agarose media. We therefore propose that this T. equiperdum IVMt1 strain is a new $T$. equiperdum reference strain. Whole genome and transcriptome analyses using this new reference T. equiperdum strain are expected to reveal the phylogenetic relationship between Trypanozoon and to be useful in the development of novel methods for diagnosing dourine.

\section{Additional files}

Additional file 1: Table S1. The PCR primers used in the present study. (DOCX $25 \mathrm{~kb}$ )

Additional file 2: Movie 1. Culture-adapted T. equiperdum IVM-t1 were proliferated on the surface of soft agarose media. (M4V 8770KB) 
Additional file 3: Figure S1. The phylogenetic tree of the 18S rRNA and ITS region. A phylogenetic analysis was performed using the $T$. equiperdum IVM-t1, SITB818, STIB841, STIB842, BoTat1.1, T. evansi Tansui (Accession No. D89527.1), Cairo (AB551922.1), KAI.2 (AY912277), Sam.2 (AY912279.1), T. brucei TREU927 (AC012647), T. b. gambiense DAL972 (FN554966.1), T. b. gambiense Tsuua (AJ009141) and T. b. rhodesiense Utro (AJ009142) sequences. A: A phylogenetic tree based on the $18 \mathrm{~S}$ rRNA sequence. B: A phylogenetic tree based on the ITS sequence. Figure S2. The maxicircle PCR of the Trypanozoon species. Gel electrophoresis images of the PCR products are shown in A to G, NADH-dehydrogenase subunit 7 (NAD7; 383 bp), Cytochrome oxidase subunit 2 (Cox2; 1747 bp), ATOas subunit 6 (A6; 299 bp), 125 ribosomal RNA (12S rRNA; 1597 bp in T. b. brucei GUTat3.1 strain and T. equiperdum STIB818 strain, $1415 \mathrm{bp}$ in T. equiperdum STIB841, STIB842, BoTat1.1 strains, respectively), NADHdehydrogenase subunit 7-cytochromeB (ND7-CyB; 1450 bp), Maxicircle unknown reading frame-NADH dehydrogenase subunit 1 (MURF-ND1; $1779 \mathrm{bp}$ ) and Maxicircle unknown reading frame 2-cytochrome oxidase subunit 1 (MURF2-Cox1; $1551 \mathrm{bp}$ ), respectively. M: the $100 \mathrm{bp}$ and $1 \mathrm{kbp}$ DNA ladders; Lanes 1 to 8 show T. b. brucei GUTat3.1, T. evansi IL3960, T. equiperdum IVM-t1, STIB818, STIB841, STIB842, BoTat1.1 strains and negative control (distilled water), respectively. (PPTX $164 \mathrm{~kb}$ )

\section{Acknowledgments}

We thank Ms. Noriko Endo and Ms. Bat-Uyanga Lhagva for their project management in Mongolia. We thank all of the Mongolian SATREPS project researchers for supporting this study. We also thank Ms. Yoko Matsushita for her excellent technical assistance. This study was financially supported by the Japan Society for the Promotion of Science (JSPS), Grants-in-Aid for Scientific Research from the Ministry of Education, Culture, Sports, Science and Technology (MEXT), and the AMED/JICA SATREPS.

\section{Funding}

This study was financially supported by the Japan Society for the Promotion of Science (JSPS), Grants-in-Aid for Scientific Research from the Ministry of Education, Culture, Sports, Science and Technology (MEXT), and the AMED/ JICA SATREPS.

\section{Availability of data and materials}

The datasets supporting the conclusions of this article are included within the article and its additional files

\section{Authors' contributions}

KS and SN helped to conceive the study and participated in its design and the laboratory experiments. B Battur, B Battsetseg and NI helped to conceive the study, participated in its design, analyzed data and helped to draft and edit the manuscript and obtain funding. SY, DO, SPM and BD helped to conceive the study, participated in its design and analyzed the data. All of the authors read and approved the final manuscript.

\section{Competing interests}

The authors declare that they have no competing interests.

\section{Consent for publication}

Not applicable.

\section{Ethics approval and consent to participate}

Not applicable.

\section{Author details}

'National Research Center for Protozoan Diseases, OIE Reference Laboratory for Surra, Obihiro University of Agriculture and Veterinary Medicine, Inada, Obihiro, Hokkaido 080-8555, Japan. ${ }^{2}$ Institute of Veterinary Medicine, Laboratory of Molecular Genetics, Mongolian University of Life Sciences, Zaisan 17024, Ulaanbaatar, Mongolia.

Received: 27 April 2016 Accepted: 12 August 2016

Published online: 31 August 2016

\section{References}

1. Brun R, Hecker H, Lun ZR. Trypanosoma evansi and T. equiperdum: distribution, biology, treatment and phylogenetic relationship (a review). Vet Parasitol. 1998;79(2):95-107.

2. Li FJ, Lai DH, Lukes J, Chen XG, Lun ZR. Doubts about Trypanosoma equiperdum strains classed as Trypanosoma brucei or Trypanosoma evansi. Trends Parasitol. 2006;22(2):55-6.

3. Claes F, Büscher P, Touratier L, Goddeeris BM. Trypanosoma equiperdum: master of disguise or historical mistake? Trends Parasitol. 2005;21(7):316-21.

4. Hagos A, Goddeeris BM, Yilkal K, Alemu T, Fikru R, Yacob HT, Feseha G, Claes F. Efficacy of Cymelarsan (R) and Diminasan (R) against Trypanosoma equiperdum infections in mice and horses. Vet Parasitol. 2010;171(3-4):200-6.

5. Pascucci I, Di Provvido A, Camma C, Di Francesco G, Calistri P, Tittarelli M, Ferri N, Scacchia M, Caporale V. Diagnosis of dourine in outbreaks in Italy. Vet Parasitol. 2013:193(1-3):30-8.

6. Clausen PH, Chuluun S, Sodnomdarjaa R, Greiner M, Noeckler K, Staak C, Zessin $\mathrm{KH}$, Schein E. A field study to estimate the prevalence of Trypanosoma equiperdum in Mongolian horses. Vet Parasitol. 2003;115(1):9-18.

7. Claes F, llgekbayeva GD, Verloo D, Saidouldin TS, Geerts S, Buscher P, Goddeeris BM. Comparison of serological tests for equine trypanosomosis in naturally infected horses from Kazakhstan. Vet Parasitol. 2005;131(3-4):221-5.

8. Vulpiani MP, Carvelli A, Giansante D, lannino F, Paganico D, Ferri N. Reemergence of dourine in Italy: clinical cases in some positive horses. J Equine Vet Sci. 2013;33(6):468-74

9. Calistri P, Narcisi V, Atzeni M, De Massis F, Tittarelli M, Mercante MT, Ruggieri E, Scacchia M. Dourine reemergence in Italy. J Equine Vet Sci. 2013;33(2):83-9.

10. Nguyen TT, Zhou M, Ruttayaporn N, Nguyen QD, Nguyen VK, Goto Y, Suzuki Y, Kawazu S, Inoue N. Diagnostic value of the recombinant tandem repeat antigen TeGM6-4r for surra in water buffaloes. Vet Parasitol. 2014;201(1-2):18-23.

11. Nguyen TT, Ruttayaporn N, Goto Y, Kawazu S, Sakurai T, Inoue N. A TeGM6-4r antigen-based immunochromatographic test (ICT) for animal trypanosomosis. Parasitol Res. 2015;114(11):4319-25.

12. Desquesnes M, McLaughlin G, Zoungrana A, Davila AM. Detection and identification of Trypanosoma of African livestock through a single PCR based on internal transcribed spacer 1 of rDNA. Int J Parasitol. 2001;31(5-6):610-4.

13. Thuy N, Goto Y, Lun ZR, Kawazu SI, Inoue N. Tandem repeat protein as potential diagnostic antigen for Trypanosoma evansi infection. Parasitol Res. 2012;110(2):733-9.

14. Herbert WJ, Lumsden WH. Trypanosoma brucei: a rapid "matching" method for estimating the host's parasitemia. Exp Parasitol. 1976:40(3):427-31.

15. Hirumi H, Hirumi K. In vitro cultivation of Trypanosoma congolense bloodstream forms in the absence of feeder cell layers. Parasitology. 1991;102(Pt 2):225-36

16. Sambrook J, Russell DW, Sambrook J. The condensed protocols from molecular cloning: a laboratory manual. Cold Spring Harbor: Cold Spring Harbor Laboratory Press; 2006.

17. Da Silva FM, Noyes H, Campaner M, Junqueira ACV, Coura JR, Añez N, Shaw $J$ J, Stevens JR, Teixeira MMG. Phylogeny, taxonomy and grouping of Trypanosoma rangeli isolates from man, triatomines and sylvatic mammals from widespread geographical origin based on SSU and ITS ribosomal sequences. Parasitology. 2004;129:549-61.

18. Lai DH, Hashimi H, Lun ZR, Ayala FJ, Lukes J. Adaptations of Trypanosoma brucei to gradual loss of kinetoplast DNA: Trypanosoma equiperdum and Trypanosoma evansi are petite mutants of T. brucei. Proc Natl Acad Sci U S A. 2008:105(6):1999-2004

19. Suganuma K, Sarwono AE, Mitsuhashi S, Jakalski M, Okada T, Nthatisi M, Yamagishi J, Ubukata M, Inoue N. Mycophenolic acid and its derivatives as potential chemotherapeutic agents targeting inosine monophosphate dehydrogenase in Trypanosoma congolense. Antimicrob Agents Chemother. 2016;60:4391.

20. Carruthers VB, Cross GAM. High-efficiency clonal growth of blood-streamform and insect-form Trypanosoma brucei on agarose plates. Proc Natl Acad Sci U S A. 1992;89(18):8818-21.

21. King SRB, Gurnell J. Effects of fly disturbance on the behaviour of a population of reintroduced Przewalski horses (Equus ferus przewalskii) in Mongolia. Appl Anim Behav Sci. 2010;125(1-2):22-9.

22. Carnes J, Anupama A, Balmer O, Jackson A, Lewis M, Brown R, Cestari I, Desquesnes M, Gendrin C, Hertz-Fowler C, et al. Genome and phylogenetic analyses of Trypanosoma evansi reveal extensive similarity to T. brucei and multiple independent origins for dyskinetoplasty. PLoS Negl Trop Dis. $2015 ; 9(1): e 3404$ 
23. Sanchez E, Perrone T, Recchimuzzi G, Cardozo I, Biteau N, Aso PM, Mijares A, Baltz T, Berthier D, Balzano-Nogueira L, et al. Molecular characterization and classification of Trypanosoma spp. Venezuelan isolates based on microsatellite markers and kinetoplast maxicircle genes. Parasit Vectors. 2015;8:536.

24. Desquesnes M, Holzmuller P, Lai DH, Dargantes A, Lun ZR, Jittaplapong S. Trypanosoma evansi and surra: a review and perspectives on origin, history, distribution, taxonomy, morphology, hosts, and pathogenic effects. Biomed Res Int. 2013;2013:194176.

25. Schnaufer A, Domingo GJ, Stuart K. Natural and induced dyskinetoplastic trypanosomatids: how to live without mitochondrial DNA. Int J Parasitol. 2002;32(9):1071-84.

26. Kaminsky R, Schmid C, Lun ZR. Susceptibility of dyskinetoplastic Trypanosoma evansi and T. equiperdum to isometamidium chloride. Parasitol Res. 1997;83(8):816-8.

27. Lun ZR, Lai DH, Wen YZ, Zheng LL, Shen JL, Yang TB, Zhou WL, Qu LH, Hide G, Ayala FJ. Cancer in the parasitic protozoans Trypanosoma brucei and Toxoplasma gondii. Proc Natl Acad Sci USA. 2015;112(29):8835-42.

Submit your next manuscript to BioMed Central and we will help you at every step:

- We accept pre-submission inquiries

- Our selector tool helps you to find the most relevant journal

- We provide round the clock customer support

- Convenient online submission

- Thorough peer review

- Inclusion in PubMed and all major indexing services

- Maximum visibility for your research

Submit your manuscript at www.biomedcentral.com/submit
Biomed Central 